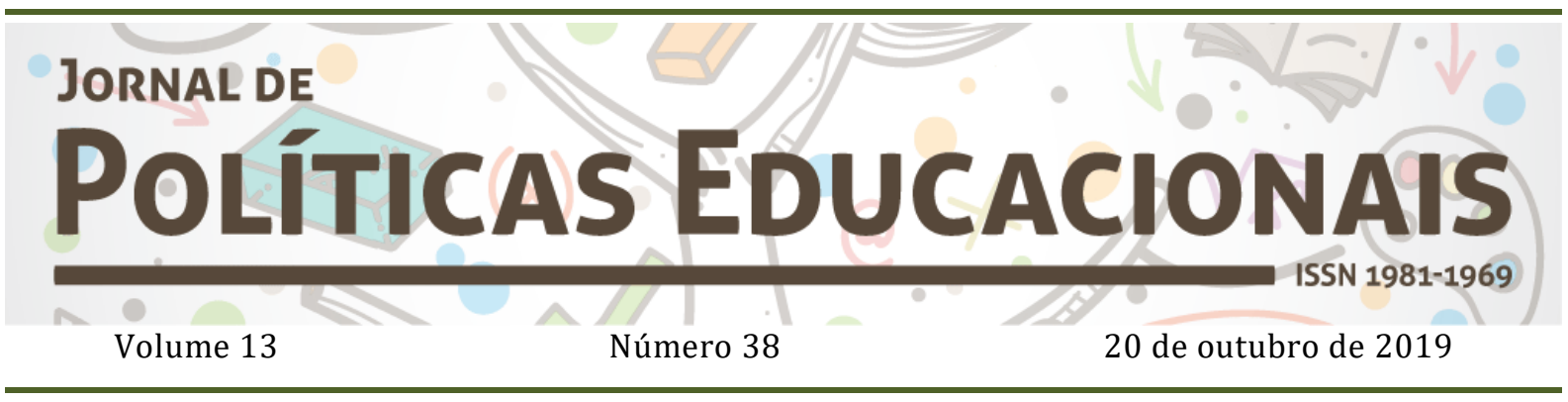

\title{
Estudo das Políticas Públicas de Formação de Professores Associado aos Resultados do IDEB dos Estados do Ceará e Maranhão
}

\section{Study of the Public Policies of Teacher Training Associated with IDEB Results of the States of Ceará and Maranhão}

\section{Estudio de las Políticas Públicas de Formación de Profesores Asociado a los Resultados del IDEB de los Estados de Ceará y Maranhão}

\author{
Maria Cristina Mesquita da Silva ${ }^{1}$ \\ Livia Maria Rassi Cerce ${ }^{2}$ \\ Renato de Oliveira Brito ${ }^{3}$
}

Citação: SILVA, M. C. M. da; CERCE, L. M. R; BRITO, R.O. de. Estudo das Políticas Públicas de Formação de Professores Associado aos Resultados do IDEB dos Estados do Ceará e Maranhão. Jornal de Políticas Educacionais. V. 13, n. 38. Outubro de 2019.

\begin{abstract}
Resumo:
Por meio deste artigo são analisadas as políticas públicas nacionais e estaduais voltadas à formação de professores e à concretização dessas políticas nos estados do Ceará e do Maranhão. 0 estudo constituiu-se em um exercício reflexivo para compreender a abrangência dessas políticas nos respectivos estados e o seu alcance junto aos profissionais aos quais se direcionam, buscando observar a possível relação das mesmas com o desempenho dos estados nas avaliações nacionais da Educação Básica, em especial no Ín dice de Desenvolvimento da Educação Básica (IDEB). A análise se sustenta na revisão bibliográfica e nos normativos e nos documentos técnico-institucionais relacionados ao tema. Considera-se que a oferta suficiente em quantidade e qualidade de políticas públicas para a formação de professores é um fator de grande relevância para a melhoria da qualidade da Educação Básica, e, consequentemente, para o incremento dos resultados das avaliações.
\end{abstract}

\footnotetext{
${ }^{1}$ Mestranda em Educação, pela Universidade Católica de Brasíla (UCB). Analista em Ciência e Tecnologia, na CAPES/MEC. Orcid: http://orcid.org/0000-0003-2158-0924. E-mail: cristina.mesquitas@gmail.com . Brasília. Distrito Federal. Brasil.

2 Doutoranda em Educação pela Universidade Católica de Brasília. Orcid: http://orcid.org/0000-00018084-7129. E-mail: profliviamaria2018@gmail.com . Brasília. Distrito Federal. Brasil.

3 Doutor e Mestre em Educação (Gestão e Políticas Públicas) e Bacharel em Direito pela Universidade Católica de Brasília. Atualmente é Docente/Pesquisador Permanente e Coordenador do Programa Stricto Sensu de Mestrado e Doutorado em Educação da Universidade Católica de Brasília. Orcid: http://orcid.org/0000-0002-9345-2529. E-mail: renatooris@gmail.com . Brasília. Distrito Federal. Brasil.
} 
Palavras-chave: Políticas públicas, formação docente, Ceará, Maranhão, IDEB.

\begin{abstract}
This article analyzes national and state public policies aimed at teacher education and the implementation of these policies in the states of Ceará and Maranhão. The study constituted a reflexive exercise to understand the comprehensiveness of these policies in the respective states and their reach with the professionals for whom they are directed, seeking to observe the possible relation between them and the states' performance in the national assessments of basic education, in particular in the Basic Education Development Index (IDEB). The analysis is based on the bibliographic review, normative and technicalinstitutional documents related to the theme. It is considered that the sufficient quantity and quality of public policies for the training of teachers is an important factor for improving the quality of Basic Education and, consequently, for increasing the results of the evaluations.
\end{abstract}

Keywords: Public policies, teacher training, Ceará, Maranhão, IDEB.

\title{
Resumen
}

Por medio de este artículo se analizan las políticas públicas nacionales y estatales dirigidas a la formación de profesores y el concretarse de esas políticas, en los estados de Ceará y de Maranhão. El estudio se constituyó de un ejercicio reflexivo para comprender el alcance de estas políticas en los respectivos estados y su alcance junto a los profesionales a los que se dirigen, buscando observar la posible relación de las mismas con el desempeño de los estados en las evaluaciones nacionales de la Educación Básica, en especial en el Índice de Desarrollo de la Educación Básica (IDEB). El análisis se sustenta en la revisión bibliográfica, en los normativos y los documentos técnico-institucionales relacionados al tema. Se considera que la oferta suficiente en cantidad y calidad de políticas públicas para la formación de profesores es un factor de gran relevancia para la mejora de la calidad de la Educación Básica y, consecuentemente, para el incremento de los resultados de las evaluaciones.

Palabras clave: Políticas públicas, formación docente, Ceará, Maranhão, IDEB.

\section{Considerações Iniciais}

A formação de professores tem sido, por anos a fio, objeto de estudos, investigações, análises e questionamentos. Os resultados apresentados nas avaliações dos mais diversos níveis, sejam eles municipais, estaduais, nacionais e internacionais, revelam como os professores estão sendo preparados para trabalhar no contexto atual, ou seja, as avaliações não são medidas pelos resultados dos estudantes, apenas os estudantes, mas também, e, principalmente, pelo desempenho dos professores que estão dia a dia em sala de aula.

O Brasil é um país de diversidades e de diferentes contextos. Neste cenário tão diverso e múltiplo, as políticas públicas educacionais têm o desafio de atender a uma imensa demanda, cujas características e necessidades nem sempre são facilmente contempladas. Fazer política para que toda essa diversidade seja atendida é um grande desafio. Assim, em parceria com a União, os estados fazem suas próprias políticas públicas para que atendam de forma mais legítima à demanda de sua população.

É propósito deste artigo realizar um estudo das políticas públicas de formação de professores do estado do Ceará, que demonstrou grande salto nos resultados do IDEB, 
comparando-as com as políticas públicas de formação de professores do estado do Maranhão, cujos resultados, em 2007, estavam bem próximos aos do Ceará, apresentando um índice de 3,7 para os estudantes do 4ํㅜㄷㅜㅜ ano do Ensino Fundamental. Apesar disso, o Maranhao não apresentou a mesma evolução em seus índices, permanecendo, em 2017, com apenas 4,8 pontos no resultado do IDEB dos estudantes da mesma etapa do Ensino Fundamental. Objetiva-se saber se as políticas públicas para a formação de professores se relacionam diretamente com os resultados alcançados, e até que ponto essa variável tem relevância suficiente para interferir nas proposições das melhorias educacionais que o país necessita.

0 artigo divide-se de modo a abordar: a contextualização das políticas públicas federais de formação de professores, as políticas públicas de formação de professores específicas do Ceará e do Maranhão e os resultados do IDEB em cada um destes contextos. Apresentam-se dados estatísticos atuais da realidade educacional dos estados estudados, bem como um panorama geral da situação da formação docente para os mesmos.

Em relação à técnica de pesquisa adotada neste artigo, destaca-se que foi utilizado uma abordagem comparativa dos cenários educacionais dos dois estados. De acordo com Manzon (2015), para a comparação realizada entre lugares deve ser considerada a unidade de análise, ou seja, quem ou o que está sendo analisado. Desta forma, procurouse utilizar unidades observacionais, sendo realizada a coleta de dados. Foram identificados pontos semelhantes e pontos diferentes em cada dado apontado, estabelecendo assim um parâmetro de comparabilidade inicial. "Em outras palavras, para ter significância, um estudo comparado deve ser capaz de identificar o grau de semelhança ou de diferença e a razão por isso, identificando as causas envolvidas e suas inter-relações" (MANZON, 2015, p. 130).

Nessa perspectiva, Bray, Adamson e Mason (2015) afirmam que um dos principais motivos de fazer comparações é apoiar futuras tomadas de decisões, mas é igualmente comum que sejam feitas comparações para justificar decisões já tomadas. Ao redor do mundo, tornam-se evidentes os diferentes fatores culturais e políticos que guiam as comparações dos formuladores de políticas.

Cumpre, adicionalmente, revelar que os estudos comparados surgem, então, com objetivos diversos:

[...]não para imitar, mas para trazer para os painéis ou mesas de discussão, outras ideias e horizontes que possam aprofundar a reflexão em torno dos nossos 
próprios desafios. A concretização de uma ideia requer o exame das condições do campo onde se pretende a sua conversão em práticas. (CUNHA, 2015, p. 21).

De acordo com Souza (2016), o principal motivo que se tem para fazer pesquisa comparada em educação entre os estados, ou até mesmo regiões do Brasil, é a descentralização do Ensino Básico, que dá autonomia para a gerência da educação.

A Constituição Republicana de 1891 manteve, pelo federalismo, a descentralização da educação, desobrigando a União da responsabilidade pelo ensino elementar e secundário, enquanto reiterava, no âmbito nacional, sua competência em relação ao ensino superior. Dessa maneira, cada estado organizou o seu sistema próprio de instrução pública investindo de forma diferenciada na modernização e expansão do ensino primário, técnicoprofissional e secundário. Consequentemente, as diferenças regionais/estaduais tornaram-se a característica marcante da educação no país. Assim, a desigualdade regional verificada continuamente nos índices de analfabetismo, no atendimento à demanda pela educação elementar e média tornou-se constitutiva da dinâmica do federalismo brasileiro assentado em diferenças sociais, econômicas e culturais. [...] No que diz respeito à história da educação no Brasil, o exercício da comparação em âmbito nacional justifica-se precisamente pelo reconhecimento da existência de diferenças na configuração da educação entre os estados e regiões do país. Além da educação, as assimetrias e desigualdades socioculturais e econômicas entre os estados valida 0 questionamento sobre os processos de transferência e contatos culturais. (SOUZA, 2016, p. 836).

Dessa forma, nesse âmbito, justifica-se a importância de comparar os estados brasileiros, Ceará e Maranhão, e analisar os pontos em que se assemelham e os itens que os diferenciam, a fim de possibilitar a análise dos resultados educacionais dos mesmos, utilizando-se para tanto os dados apresentados no IDEB destes estados.

\section{As Políticas Públicas de Formação de Professores}

O conceito de políticas públicas pode ter diferentes interpretações, podendo ser visto como soluções específicas de como manejar assuntos, ou mesmo como um conjunto de atividades que dizem respeito à ação do governo (DIAS; MATOS, 2012). Dessa forma, é possível afirmar que se tratam de políticas públicas as ações governamentais que visam atingir objetivos, somando-se em um conjunto de procedimentos. 0 principal objetivo das políticas públicas é gerar o bem comum, ou seja, possibilitar o acesso e a garantia de direitos equânimes a determinados setores da sociedade, aplicando-se enquanto promotoras de estratégias para solucionar problemas públicos.

Ainda de acordo com Dias e Matos (2012), as políticas públicas têm estabilidade e adaptabilidade, ou seja, mesmo que sofram alterações graduais por conta do tempo e das 
necessidades socioeconômicas, devem se manter estáveis no sentido de que os governos que passam por elas não as alterem de forma aleatória; devem ter coerência e coordenação, apresentando compatibilidade com outras políticas públicas; não podem ser fragmentadas, e, por fim, devem ser constantemente avaliadas. É importante ainda que elas tenham qualidade na implementação e que sua aplicação seja efetiva, pois isso fará com que sejam eficazes, levando em consideração o interesse público, e sendo eficientes em sua proposta, na sua aplicação e no manuseio dos recursos necessários.

Desta forma, instituir políticas públicas que cuidem de determinados setores da sociedade faz com que a garantia dos direitos chegue a todas as pessoas. Na educação há, além do direito de uma educação de qualidade, a garantia de uma formação docente de qualidade, que atenda aos objetivos e aos propósitos da educação nacional. Miguel e Ferreira (2015, p. 30) discutem acerca da complexidade dessas ações, afirmando: "Podemos conceber as políticas docentes como uma teia complexa com múltiplas influências".

As últimas décadas tornaram o Brasil o palco de grandes transformações no setor das políticas públicas educacionais, isso porque os indicadores quase sempre apontavam para níveis insuficientes e insatisfatórios na Educação Básica. De acordo com Alves e Costa-Hübes (2011, p. 379), “a formação básica não dava conta de atender aos propósitos das transformações impostas pelas políticas educacionais do país". Nesse sentido, surgiram uma série de políticas públicas direcionadas à formação docente, cujo objetivo é formar professores para a prática pedagógica de forma eficiente.

Conforme Luckesi (2005, p. 20), "necessitamos formar educadores que, para si mesmos e para os outros, sejam capazes de cuidar de si, de conviver com os outros e de ter a posse do conhecimento científico e profissional de sua área de atuação", visto que a formação de professores é condição fundamental para a qualidade de ensino. Promover a formação de professores da Educação Básica é um dever do Estado, assegurado em leis, decretos e resoluções. Entretanto, a forma com que essa formação acontece difere de um lugar para outro, pois há uma diferença entre o garantir e o implementar de fato essa formação.

A fim de assegurar a formação adequada dos professores e pautada na Constituição Federal de 1988 (BRASIL, 1988), a Lei de Diretrizes e Bases da Educação (LDB) n. 9.394/96 (BRASIL, 1996) instituiu um grau mais alto de formação aos professores da 
Educação Básica (em comparação com as legislações anteriores), estabelecendo um marco e, ao mesmo tempo, um desafio aos sistemas educacionais:

Art. 62. A formação de docentes para atuar na educação básica far-se-á em nível superior, em curso de licenciatura, de graduação plena, em universidades e institutos superiores de educação, admitida, como formação mínima para o exercício do magistério na educação infantil e nas quatro primeiras séries do ensino fundamental, a oferecida em nível médio, na modalidade Normal. (BRASIL, 1996).

A formação de professores assumiu uma nova conotação com a exigência do nível superior para atuação em toda a Educação Básica. Para a atuação na Educação Infantil e nas séries iniciais do Ensino Fundamental, consentiu-se a formação em nível médio (Curso Normal). No entanto, conforme entendimento de Borges, Aquino e Puentes (2011, p. 101), a lei não garantiu uma formação adequada, pois esta foi vista como "aligeirada e barata", não atingindo as expectativas esperadas.

No período que sucedeu à promulgação da LDB, o Curso de Pedagogia teve um crescimento significativo. Segundo a Sinopse Estatística da Educação Superior, organizada pelo Instituto Nacional de Estudos e Pesquisas Educacionais Anísio Teixeira INEP (BRASIL, 2011), o número de matriculados passou de 222.476 em 2001, para 586.651 em 2011, ou seja, um crescimento de 163,7\% nas matrículas. Os dados revelam aumento expressivo também na Educação a Distância (EaD), que passou de 1.570 matrículas em 2001, para 281.548 em 2011, ou seja, uma ampliação de 178 vezes. No cenário atual, temos no Brasil cerca de 2,2 milhões de docentes. 0 Curso de Pedagogia é o $3^{\circ}$ maior em número de ingressantes e o $2^{\circ}$ maior em número de concluintes.

A Educação Básica representa, assim, segundo Barretto (2015, p. 681), "um celeiro fértil para a formação de professores e certamente um mercado de trabalho de proporções inusitadas para os docentes". Ainda assim, parte significativa dos professores que atuam na Educação Básica brasileira não tem Ensino Superior ou não o tem na área em que atuam. E, por ser um país de grandes dimensões, não apenas em extensão física, mas também em diversidade cultural e socioeconômica, pode-se perceber a discrepância entre a formação de professores nas diferentes regiões. Enquanto no Sudeste $84 \%$ dos professores possuem formação em nível superior, no Nordeste apenas 64\% possuem essa formação. 0 gráfico abaixo mostra a distribuição dos docentes do Brasil no ano de 2017, que atuam na Educação Básica, por nível de escolaridade. 
SILVA, M. C. M. da; CERCE, L. M. R; BRITO, R. O. de. Estudo das Políticas Públicas de Formação de Professores Associado aos Resultados do IDEB dos Estados do Ceará e Maranhão

Gráfico1 - Distribuição dos docentes da Educação Básica do Brasil por nível de escolaridade

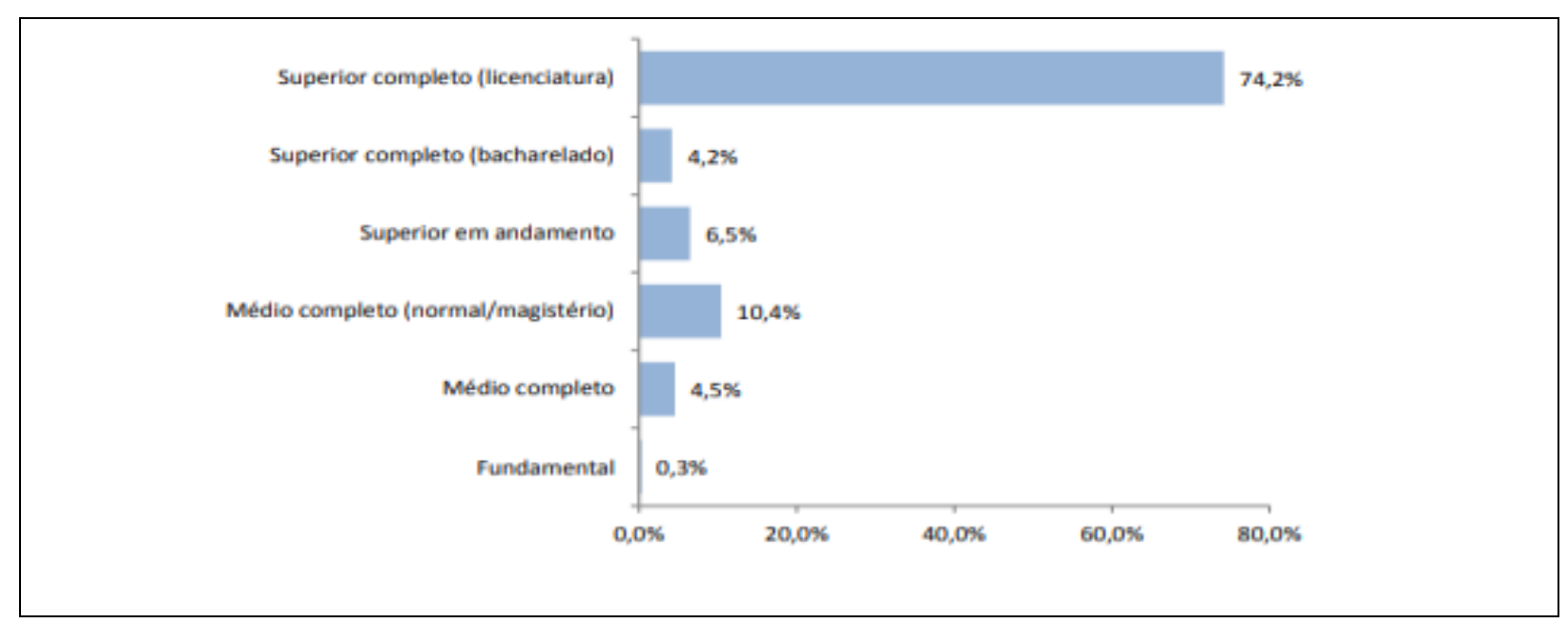

Fonte: INEP - Censo Escolar 2017. Notas Estatísticas (BRASIL, 2018b).

Os dados apontam que temos em torno de 2,2 milhões de professores atuando na Educação Básica brasileira, dos quais 63,8\% atuam no Ensino Fundamental, correspondendo a mais de 1,4 milhões de professores nesta etapa da Educação Básica. Revela-se que 78,4\% (em torno de 1,1 milhão) dos professores que atuam na educação básica possuem nível Superior Completo, e, dos professores com graduação, 94,7\% (pouco mais de 1 milhão de professores) têm curso de Licenciatura.

Para o agrupamento e classificação das situações de formação dos docentes, o INEP propõe cinco grupos distintos ${ }^{4}$, os quais ilustram os cenários compostos a partir da análise da formação docente no país. Os mapas das figuras 1 e 2 apresentam, respectivamente, o percentual de disciplinas ministradas por professores com formação adequada nos anos iniciais do Ensino Fundamental (1ํㅜ ao 5ํano) e o cenário referente ao percentual de disciplinas que são ministradas por professores com formação adequada nas séries finais do Ensino Fundamental ( $6^{\circ}$ ao $9^{\circ}$ ano).

\footnotetext{
${ }^{4}$ Grupo 1 - Percentual de disciplinas que são ministradas por professores com formação superior de licenciatura (ou bacharelado com complementação pedagógica) na mesma área da disciplina que leciona;

Grupo 2 - Percentual de disciplinas que são ministradas por professores com formação superior de bacharelado (sem complementação pedagógica) na mesma área da disciplina que leciona;

Grupo 3 - Percentual de disciplinas que são ministradas por professores com formação superior de licenciatura (ou bacharelado com complementação pedagógica) em área diferente daquela que leciona;

Grupo 4 - Percentual de disciplinas que são ministradas por professores com formação superior não considerada nas categorias;

Grupo 5 - Percentual de disciplinas que são ministradas por professores sem formação superior.
} 
Figura 1 - Formação de Professores nos anos iniciais do Ensino Fundamental

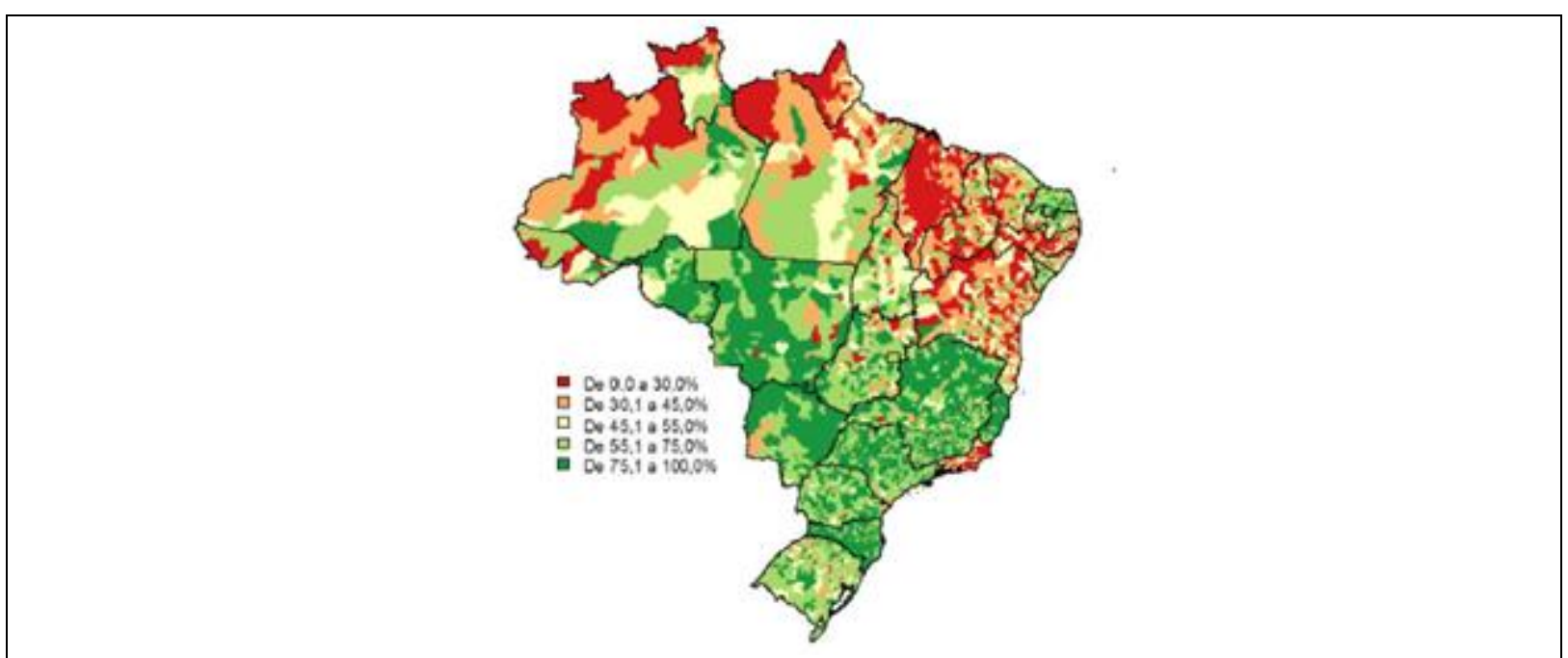

Fonte: INEP - Censo Escolar 2017. Notas Estatísticas (BRASIL, 2018b).

Nota-se, analisand o a figura 1, que a Região Nordeste, as regiões limítrofes da Região Norte e o estado do Espírito Santo são os que apresentam os percentuais mais baixos de adequação da formação de professores para atuação na primeira etapa do Ensino Fundamental. Vale destacar que, nesta etapa, a formação requerida corresponde à formação em cursos de Pedagogia.

Com relação à figura 2, verifica-se que, ressalvadas algumas exceções, as regiões Norte, Nordeste e Centro-Oeste têm menos da metade de seus professores com a formação adequada à área em que atuam. Em todo esse imenso território, apenas o Distrito Federal encontra-se em situação próxima ao adequado. Nas outras regiões, embora os indicadores apontem situação mais favorável, apenas o estado do Paraná tem a maioria dos municípios se aproximando do percentual de formação requerido.

As análises sinalizam para a heterogeneidade das situações de formação dos professores pelo país quando isoladas nas duas etapas do Ensino Fundamental. Impossível não concluir que ainda há um longo caminho a percorrer para que nos aproximemos dos índices ideais de formação no que se refere ao aspecto da adequação entre a habilitação do professor e a disciplina que leciona. 
Figura 2 - Formação de Professores nos anos finais do Ensino Fundamental

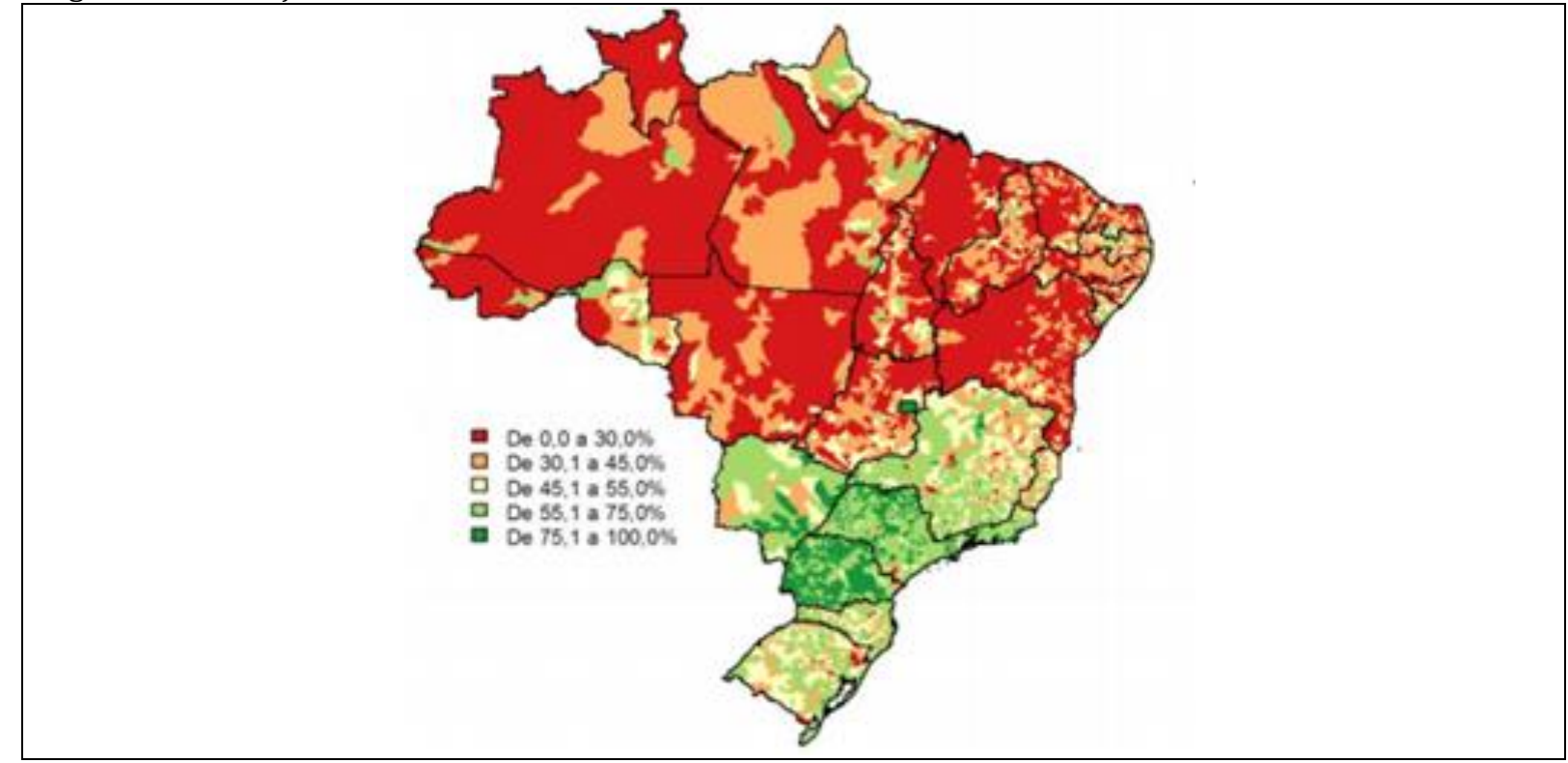

Fonte: Censo Escolar 2017. Notas Estatísticas (BRASIL, 2018b).

Tem-se, assim, uma noção da dimensão dos desafios que se impõem ao Estado brasileiro, com algumas de centenas de milhares de professores em exercício a formar, além dos futuros professores, que deverão ocupar os postos que se apresentarão nos próximos anos. Nesse contexto, os programas de formação docente emergem com o objetivo de garantir a qualificação mínima necessária e melhorar a qualidade da formação dos professores para a melhoria da qualidade do ensino, o que se refletirá no aumento dos indicadores educacionais.

Para dar conta da formação de qualidade dos professores e a fim de promover um ensino também de qualidade, a Coordenação de Aperfeiçoamento de Pessoal de Nível Superior (CAPES), um dos órgãos federais responsáveis por gerenciar e fomentar o cumprimento das políticas públicas de formação de professores, oferece os seguintes programas: o Sistema Universidade Aberta do Brasil (UAB), Programa Nacional de Formação de Professores (PARFOR), Programa Institucional de Bolsas de Iniciação à Docência (PIBID) e Residência Pedagógica (RP) ${ }^{5}$.

Instituído pelo Decreto n. 5.800/2006 (BRASIL, 2006), o Sistema UAB oferta cursos de licenciatura de formação inicial e continuada para professores, por meio da Educação a Distância (EaD). Há atualmente no Brasil 777 polos de apoio presencial do Sistema UAB

\footnotetext{
${ }^{5}$ Os dados apresentados adiante, a respeito de cada um dos programas, foram obtidos a partir dos relatórios e sistemas disponibilizados pelas Diretoria de Educação a Distância e Diretoria de Formação de Professores da Educação Básica (DED e DEB/CAPES).
} 
ativos em funcionamento (BRASIL, 2019), sendo que na Região Nordeste estão 295, a maioria deles. Das 100 mil vagas ofertadas por meio do Edital CAPES n. 05/2018 (BRASIL, 2018a) para os anos de 2018 e 2019, 35.050 estão na Região Nordeste.

0 quadro 1, a seguir, apresenta a situação do Sistema UAB nos estados do Maranhão e do Ceará em março/2019:

Quadro 1- O Sistema UAB no Maranhão e no Ceará

\begin{tabular}{|c|c|c|c|c|}
\hline Estado & Instituições & Polos & Alunos cursando & Formados \\
\hline MA & 3 & 37 & 10.963 & 6.108 \\
\hline CE & 6 & 43 & 8.238 & 7.104 \\
\hline
\end{tabular}

Fonte: Elaborado pelos autores, com base nos dados DED/CAPES.

Outro programa de formação de professores sob a gestão da CAPES, o PARFOR, diferencia-se da UAB por concentrar-se na oferta de cursos na modalidade presencial, oferecendo cursos de primeira e segunda licenciatura exclusivamente aos professores que já atuam na rede pública da Educação Básica, mas que ainda não têm formação específica na área de atuação. Estão matriculados no PARFOR 8.823 professores da Região Nordeste. Esta é a segunda maior região do país em número de matrículas do Programa.

No estado do Ceará são 2.190 professores cursistas, vinculados a quatro instituições de ensino superior (IES), em 31 diferentes municípios. No Maranhão, têm-se duas IES que oferecem cursos do PARFOR para 2.517 professores cursistas, em 27 municípios do estado.

O PIBID tem como proposta proporcionar aos estudantes que estão na primeira metade do curso de licenciatura uma aproximação prática com o cotidiano das escolas públicas de Educação Básica. 0 programa permite que os professores das Instituições de Ensino formadoras orientem os seus estudantes em projetos de integração prática. Para isso, é realizada a concessão de bolsas tanto para os professores, coordenadores e supervisores dos projetos, quanto para os estudantes. Participam do programa 280 IES em todo o país.

A maior parte das bolsas concedidas pelo PIBID está na Região Nordeste, que responde por 33,5\% das cotas, ou seja, 17.780 bolsas. No estado do Ceará, atualmente, são nove IES participantes do Programa, com um total de 2.096 estudantes bolsistas, em 
cinco diferentes municípios (Crato, Fortaleza, Juazeiro, Redenção e Sobral). No Maranhão, por sua vez, no mesmo período, são apenas três as IES vinculadas ao Programa, todas elas localizadas na capital, São Luís, totalizando 919 estudantes bolsistas.

O Programa Residência Pedagógica visa aperfeiçoar a formação prática nos cursos de licenciatura, por meio da imersão do licenciando que está na segunda metade do curso, na escola de Educação Básica. Os estudantes são orientados por professores da IES formadora e acompanhados pelos professores da Educação Básica. Há no Nordeste 55 IES participantes desse programa, sendo 23,71\% do total nacional. Com 16.091 cotas disponíveis, a Região Nordeste é a maior de todas as regiões do Brasil em número de beneficiários do Programa.

No Ceará, são oito IES participantes do Programa, em cinco municípios (Crato, Fortaleza, Juazeiro, Redenção e Sobral), os mesmos em que se localizam os projetos do PIBID, totalizando 2.074 residentes em todo o estado. No Maranhão, temos a participação apenas da capital do estado no Programa, com três IES, totalizando 1.282 residentes no estado.

Mesmo diante da variedade de programas de formação de professores existentes e de uma significativa oferta nos estados aqui analisados, entende-se que há ainda a necessidade de ampliar o leque de opções de formação aos professores e estabelecer programas eficazes que alcancem melhores resultados. A seguir, passa-se à verificação das políticas de formação docentes estabelecidas em nível local, pelo Maranhão e pelo Ceará.

\section{Ceará e Maranhão: Distintos Cenários Educacionais, Imensos Desafios}

O Plano Nacional de Educação (PNE), aprovado pela Lei n. 13.005/2014, estabelece diretrizes, metas e estratégias para a educação brasileira no decênio 2014-2024, contemplando todos os níveis, modalidades e etapas da educação, além de estabelecer metas e diretrizes relacionadas à profissão docente, financiamento do ensino e modelo de gestão escolar (gestão democrática). 0 documento está dividido em 20 grandes Metas, as quais são compostas por 254 Estratégias no total. (BRASIL, 2014).

A Meta 7 do PNE, "Aprendizado adequado na idade certa", remete à melhoria da qualidade da Educação Básica às médias nacionais para o IDEB, sugerindo uma relação entre o alcance dos objetivos de aprendizagem estipulados pela Base Nacional Comum Curricular (BNCC) e a melhoria do IDEB. A Meta 15, "Formação de Professores", trata da 
garantia do estabelecimento da política nacional de formação dos profissionais da educação e de assegurar a formação específica necessária a todos os professores da Educação Básica. A Meta 16, "Formação Continuada e Pós-graduação de Professores”, também se refere à garantia de formação dos professores, em nível de Pós-Graduação (50\% dos professores da Educação Básica) e da garantia da formação continuada a esses profissionais.

Em consonância com o PNE, os estados criaram os seus Planos Estaduais de Educação (PEE). 0 PEE do Ceará foi instituído pela Lei Estadual n. 16.025, de 30 de maio de 2016 (CEARÁ, 2016), passados dois anos da promulgação do PNE. O PEE do Maranhão, por sua vez, foi aprovado pela Lei Estadual n. 10.099, de 11 de junho de 2014 (MARANHÃO, 2014). Os quadros a seguir apresentam o cotejamento entre cada uma das metas dos PEE e do PNE, referentes à formação de professores e à avaliação de desempenho dos estudantes (IDEB e outros).

Nota-se, a partir do cotejamento das metas relacionadas à avaliação de desempenho dos estudantes, textos similares no que se refere à meta em si. Merece destaque o PEE do Ceará, que, para além do IDEB, se propõe à melhoria das médias de seus índices também no Exame Nacional do Ensino Médio (ENEM) e no Programa Internacional de Avaliação de Estudantes - Programme for International Student Asiesssment (PISA). Dos textos dos PEE, destacaram-se as Estratégias 7.1 e 8.1, respectivamente. Nestas, observa-se distinção quanto às propostas de cada um dos estados, pois enquanto o Ceará se propõe a instituir um programa de formação continuada de professores, o Maranhão define como primeira estratégia a criação de um indicador de qualidade educacional para o estado. 
Quadro 2 - Comparação entre os Planos Nacional e Estaduais de Educação - Avaliação de Desempenho dos Estudantes

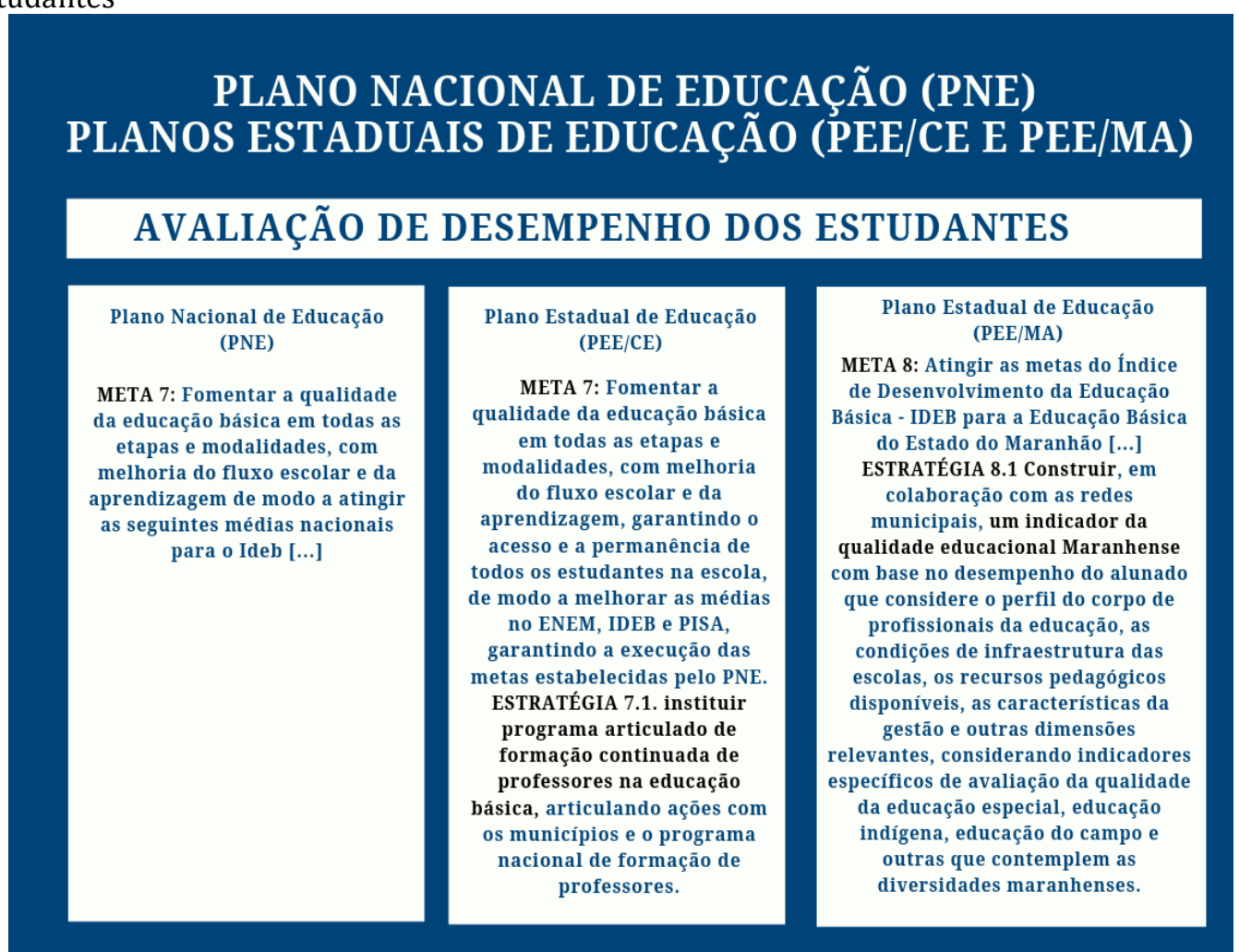

Fonte: Elaborado pelos autores, com base nas Leis de Referência.

No que se refere à formação inicial de professores, o PNE e os PEE do Maranhão e do Ceará também têm textos muito semelhantes. Sutis diferenças entre as metas são notadas entre os estados, contudo, na medida em que o Maranhão se propõe a garantir a sua política estadual de formação e valorização docente, o Ceará, para além disso, se propõe a apoiar a criação da Política Nacional. 0 estado do Ceará inclui ainda em sua Meta 15 a proposta de "[...] elevar gradualmente o número dos profissionais não docentes de nível superior", assentando aí sua proposta no que se refere aos demais profissionais da educação (ou seja, os não professores). (CEARÁ, 2016). 
Quadro 3 - Comparação entre os Planos Nacional e Estaduais de Educação - Formação Inicial de Professores

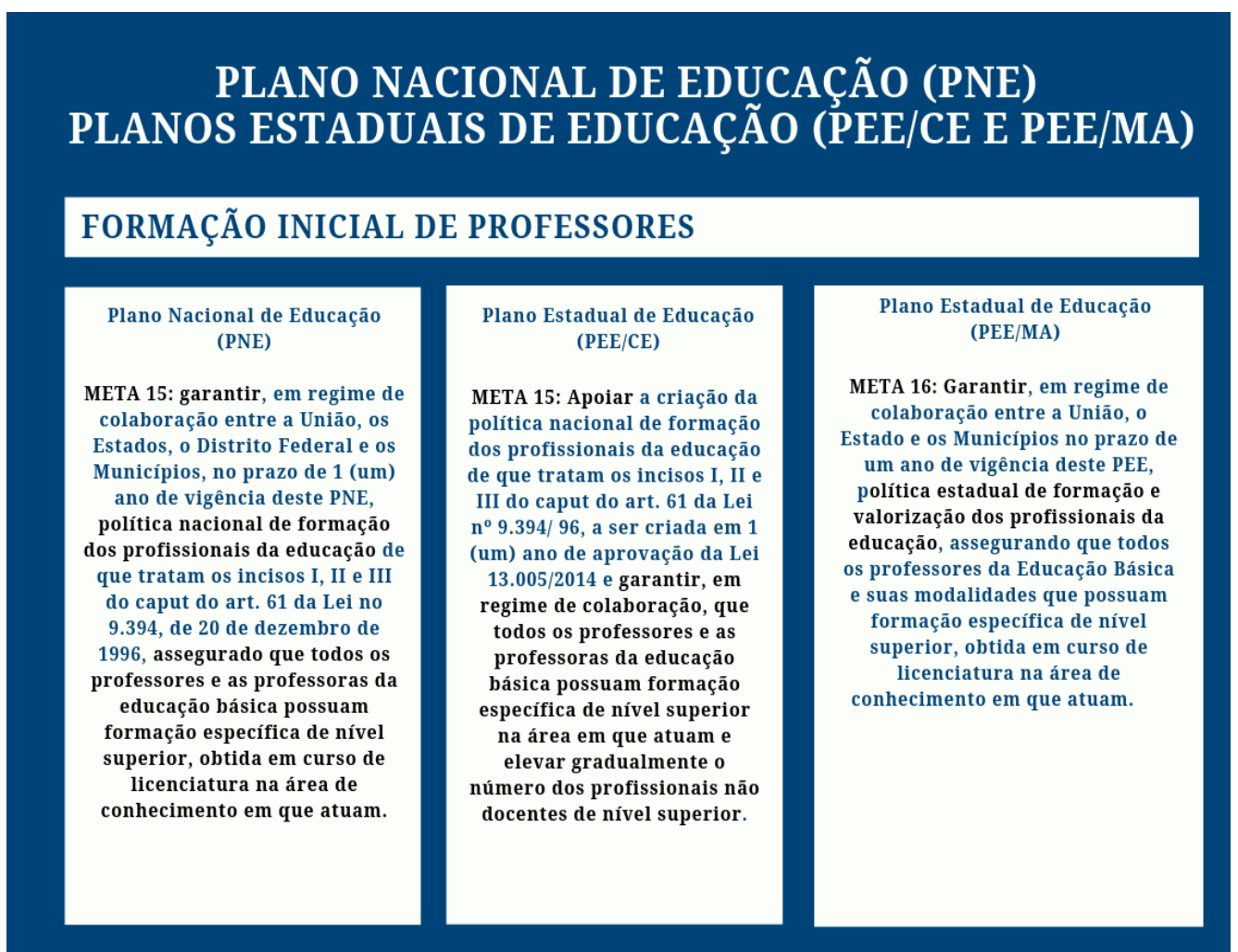

Fonte: Elaborado pelos autores, com base nas Leis de Referência.

Finalmente, no tocante à formação continuada dos professores e em nível de PósGraduação, chama atenção a distinção entre o percentual de professores a formar no referido nível estabelecido pelo Maranhão. Distinguindo-se do Ceará e da União, a meta do estado foi estabelecida em 40\% dos professores formados em nível de Pós-Graduação. Acentue-se que esta formação abrange tanto a Pós-Graduação lato sensu quanto a PósGraduação em nível stricto sensu. Em relação à formação continuada, não há distinção entre as metas. 
Quadro 4 - Comparação entre os Planos Nacional e Estaduais de Educação - Formação Continuada de Professores

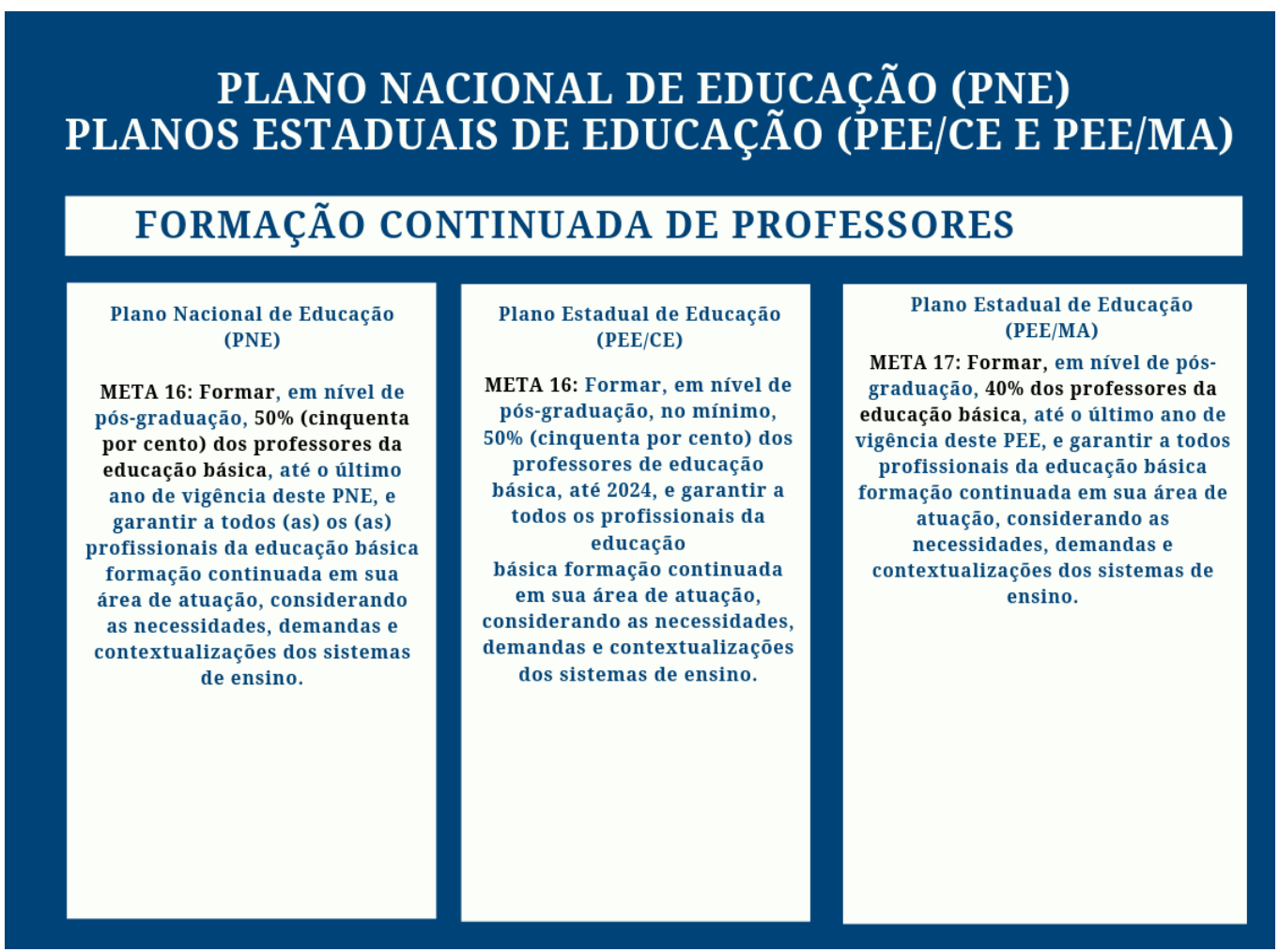

Fonte: Elaborado pelos autores, com base nas Leis de Referência.

Com relação à temática das políticas públicas voltadas à formação continuada de professores, no Ceará, esta integra a Secretaria da Educação do Estado do Ceará (SEDUCCE), a Coordenadoria de Formação Docente e Educação a Distância (CODED/CED). Esta Coordenadoria é a responsável pela formação continuada e em serviço dos professores do estado nas diferentes modalidades de ensino. A CODED oferece uma variedade de cursos para os professores, sendo a maior parte deles por meio da modalidade a distância. 0 catálogo dos cursos ofertados pela CODED é extenso e variado, perfazendo mais de 40 cursos para os professores dos diversos segmentos. A candidatura do professor se dá por meio de inscrição online e/ou por meio de editais de processos seletivos simplificados. Professores efetivos e temporários podem se candidatar aos cursos.

Já o Maranhão possui um programa chamado Escola Digna, que se constitui como uma macropolítica de educação da Secretaria de Educação do Estado (SEDUC-MA). 0 programa visa promover ações voltadas para a qualificação e formação continuada dos profissionais da educação, para ampliação da gestão democrática e do direito fundamental a uma escola de qualidade para todas as escolas maranhenses. Entre os objetivos específicos da macropolítica de educação destacam-se: 
- implementar, coordenar e avaliar ações voltadas para o desenvolvimento de uma política curricular, visando envolver técnicos e equipes escolares na implementação de mudanças no Ensino Médio que possibilitem garantir a todos os estudantes aprendizagem de qualidade na perspectiva integral;

- propor, acompanhar e avaliar ações de formação continuada dos profissionais da Rede Estadual e das Secretarias Municipais, fortalecendo o Regime de Colaboração entre estado e municípios; [...]

Não foram localizadas ações concretas de formação docente ofertadas no âmbito da SEDUC-MA. O Caderno de Orientações Pedagógicas (Gestor Escolar) do Programa Escola Digna, prevê:

\begin{abstract}
A proposta é realizar formação continuada de gestores/as, coordenadores/as pedagógicos/as e docentes que atuam na Educação Infantil e no Ensino Fundamental regular e na modalidade EJA. A estes profissionais serão entregues Cadernos de Orientações Pedagógicas, compostos por 3 volumes: Gestão Escolar, Avaliação da Aprendizagem e Organização Curricular e Práticas de Ensino para instrumentalizar a qualificação desses profissionais a fim de impactar na melhoria dos indicadores educacionais, por conseguinte na redução da pobreza e das desigualdades sociais. (MARANHÃO, 2017, p. 11 - grifo nosso).
\end{abstract}

As ações ofertadas pela SEDUC-MA sinalizam estar voltadas para a autoformação dos professores, pois a proposta, baseada no Caderno de Orientações Pedagógicas, é que haja instrumentalização da qualidade para os profissionais, havendo referências do que é esperado para que se alcance a melhoria dos indicadores educacionais.

\title{
O IDEB nos estados do Maranhão e do Ceará
}

Sistematizado e gerido pelo INEP, o Sistema de Avaliação da Educação Básica (SAEB) é composto por um conjunto de avaliações externas em larga escala, com as quais se realiza um diagnóstico da Educação Básica brasileira, fornecendo aos profissionais envolvidos e demais cidadãos um indicativo sobre a qualidade do ensino ofertado. Compõem o SAEB, a Avaliação Nacional da Educação Básica (ANEB), a Prova Brasil e a Avaliação Nacional da Alfabetização (ANA).

O IDEB é calculado a partir dos dados sobre aprovação obtidos no Censo Escolar e das médias de desempenho obtidas no SAEB. 0 índice varia de 0 a 10, combinando em si as dimensões de fluxo e aprendizagem. As metas projetadas são apresentadas 
bienalmente desde o ano de 2007, e são diferentes para cada unidade, rede e escola. Estabeleceu-se como meta nacional para o Brasil a nota 6,0, a qual deverá ser atingida até o ano de 2022. 0 quadro 5 mostra a série histórica dos resultados do IDEB das séries iniciais (4ํํํํaa anos) dos estados do Maranhão e Ceará.

Quadro 5 - Resultados do IDEB do Maranhão e Ceará

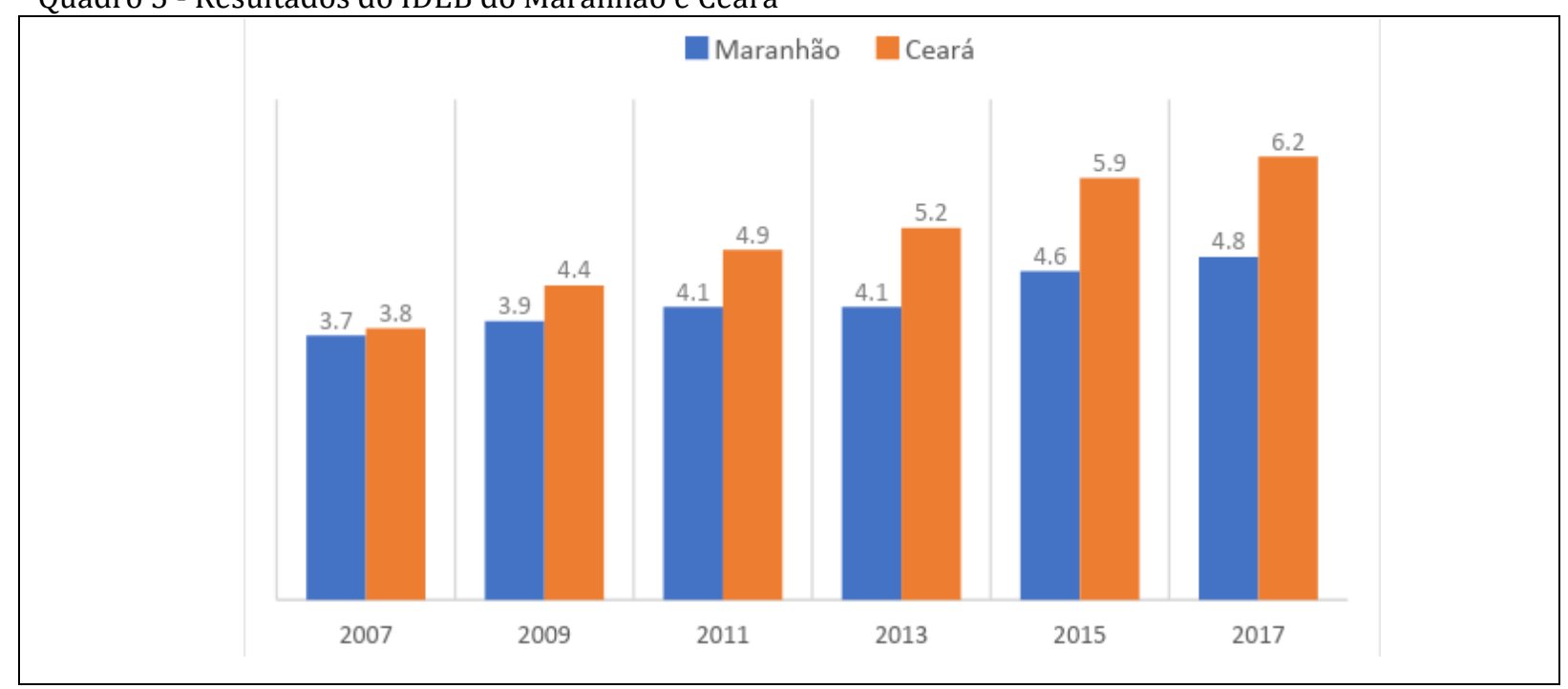

Fonte: Elaborado pelos autores a partir dos dados do INEP/MEC-2019.

As diferenças regionais podem se dar devido a uma série de variáveis, dentre as quais também merece destaque, por sua importância e impacto nos resultados, a questão socioeconômica. Essa variável passa a ser considerada neste estudo, uma vez que o Maranhão está classificado com os municípios de menor renda per capita mensal do Brasil ( $\mathrm{R} \$ 644,05$ - o município de menor renda), enquanto o Ceará está em 3o lugar ( $\mathrm{R} \$$ 1.508,09 - o município de menor renda per capita).

A relação "Nível socioeconômico x IDEB" deve ser objeto de atenção dos governos para que elaborem políticas públicas que atendam às necessidades dos municípios com nível socioeconômico mais baixo. Enquanto a média do IDEB para esses municípios é de 3,6, a média para os municípios com níveis socioeconômicos mais altos é de 7,2. Outrossim, destaca-se o reflexo do investimento que é feito na educação, enquanto, em média, os municípios maranhenses dispõem de $\mathrm{R} \$ 3.400,00$ por estudante/ano, os municípios cearenses dispõem de $\mathrm{R} \$ 3.800,00$ por estudante/ano. Em São Paulo, essa média é de $\mathrm{R} \$ 6.500,00$.

Além das diferenças entre as políticas públicas, apesar da disparidade entre o investimento na educação, há outros dados que devem ser analisados, a fim de contextualizar um pouco mais a situação dos estados analisados, conforme ilustra o quadro a seguir: 
Quadro 6 - Dados socioeconômicos e educacionais do Maranhão e do Ceará

\begin{tabular}{|l|c|l|l|l|l|l|l|l|}
\hline & $\begin{array}{l}\text { Total de } \\
\text { Municípios }\end{array}$ & $\begin{array}{l}\text { Extensão } \\
\text { Territorial }\end{array}$ & Habitantes & $\begin{array}{l}\text { Renda } \\
\text { Média }\end{array}$ & $\begin{array}{l}\text { Matrículas } \\
\text { na Ed } \\
\text { Básica }\end{array}$ & $\begin{array}{l}\text { Prof. } \\
\text { Com } \\
\text { nível } \\
\text { superior }\end{array}$ & $\begin{array}{l}\text { Escola pública } \\
\text { com } \\
\text { infraestrutura } \\
\text { adequada }\end{array}$ & $\begin{array}{l}\text { Escola } \\
\text { com } \\
\text { biblioteca }\end{array}$ \\
\hline Maranhão & 271 & 332 mil km & 6,9 milhões & $\begin{array}{l}\mathrm{R} \$ \\
947,19\end{array}$ & 2.034 .796 & $51,5 \%$ & $71,1 \%$ & $15,2 \%$ \\
\hline Ceará & 184 & 149 mil km & 8,9 milhões & $\begin{array}{l}\mathrm{R} \$ \\
1.222,43\end{array}$ & 2.210 .221 & $71,1 \%$ & $89,4 \%$ & $55,1 \%$ \\
\hline
\end{tabular}

Fonte: Anuário Brasileiro da Educação Básica - Todos pela Educação (CRUZ; MONTEIRO, 2018).

Os dados revelam a situação educacional dos estados do Maranhão e do Ceará, desnudando as suas diferenças, não somente populacionais e territoriais, mas também no que se refere ao investimento na educação. Apesar de o Maranhão ser um estado maior, tanto em extensão territorial quanto em número de municípios, ele é menor em habitantes, em renda média per capita e em matrículas na Educação Básica.

Sendo o Ceará um estado que tem a maioria de suas escolas com infraestrutura adequada, com biblioteca e com mais de 70\% dos seus professores com formação em nível superior, os dados refletem diretamente no quadro 7, que demonstra para cada 100 estudantes que ingressam na Educação Básica, o quantitativo dos que concluem as etapas.

Quadro 7 - Dados de conclusão das etapas da Educação Básica do Maranhão e do Ceará

\begin{tabular}{|l|c|c|c|}
\hline & $\begin{array}{c}\text { Concluem o } \\
\text { Fundamental I aos } \\
\text { 12 anos }\end{array}$ & $\begin{array}{c}\text { Concluem o } \\
\text { Fundamental II aos } \\
\text { 16 anos }\end{array}$ & $\begin{array}{c}\text { Concluem o Ensino } \\
\text { Médio aos 19 anos }\end{array}$ \\
\hline Maranhão & 84 & 67 & 54 \\
\hline Ceará & 92 & 76 & 58 \\
\hline
\end{tabular}

Fonte: Anuário Brasileiro da Educação Básica - Todos Pela Educação (CRUZ; MONTEIRO, 2018).

0 quadro 7 sinaliza também quanto à evasão existente durante o processo educativo e à vida escolar dos alunos nos respectivos estados. Apenas um pouco mais da metade dos estudantes que iniciam a sua vida escolar, entrando no Ensino Fundamental I, chegam ao final do Ensino Médio, sendo que nesta etapa da Educação Básica os dois estados se aproximam em seus números. 
Todos os dados observados nos dois estados em tela sinalizam para a necessidade de mudanças urgentes na educação, especialmente no que se refere à formação dos professores.

\section{A Qualidade da Educação}

Medir ou refletir sobre a qualidade na educação não é simples e não pode ser resumido apenas às análises de dados isolados. De acordo com Dourado e Oliveira (2009, p. 202), “A educação [...] é perpassada pelos limites e possibilidades da dinâmica pedagógica, econômica, social, cultural e política de uma dada sociedade”. Ou seja, ela se articula em diferentes dimensões, que, de acordo os autores, constituem-se como intra e extraescolares, que por sua vez devem articular-se entre si para a obtenção de melhores resultados.

Para os autores, trata-se de um complexo e grande desafio. Se antes se buscava acesso e permanência, hoje busca-se a melhoria na aprendizagem, ou seja, uma aprendizagem significativa. Os autores revelam que a qualidade da educação se apresenta como um fenômeno complexo, abrangente, que envolve múltiplas dimensões, não podendo ser apreendido apenas por um reconhecimento da variedade e das quantidades mínimas de insumos indispensáveis ao desenvolvimento do processo de ensinoaprendizagem, nem, muito menos, pode ser apreendido sem tais insumos.

\footnotetext{
Em outros termos, a qualidade da educação envolve dimensões extra e intraescolares e, nessa ótica, devem se considerar os diferentes atores, a dinâmica pedagógica, ou seja, os processos de ensino-aprendizagem, os currículos, as expectativas de aprendizagem, bem como os diferentes fatores extraescolares que interferem direta ou indiretamente nos resultados educativos. (OLIVEIRA; DOURADO, 2009, p. 205).
}

Nesse sentido, considera-se como fator extraescolar as questões de espaço e obrigações do Estado. 0 espaço se refere às questões socioeconômicas e culturais às quais a escola está submetida, o que, segundo os autores, está diretamente relacionado à qualidade da educação que é ofertada. A segunda questão analisada está relacionada com as obrigações do Estado, que é quem define os padrões de qualidade e a igualdade de condições de acesso.

No que se refere às questões intraescolares, os autores apontam: o plano do sistema - se referindo à estrutura física: laboratórios, bibliotecas, equipamentos, serviços de apoio; ao plano da escola - apontando para a gestão administrativa, financeira e 
pedagógica, aos programas curriculares e às metodologias; ao plano do professor - que tratando da titulação, vínculo de trabalho, dedicação, valorização e incentivo; e ao plano do aluno - que se refere ao acesso, permanência e ao desempenho escolar, ao processo avaliativo e ao processo de ensino-aprendizagem.

A qualidade, segundo Dourado e Oliveira, é determinada pelos parâmetros internacionais. No entanto,

\begin{abstract}
Ao considerar o caso brasileiro, em que a oferta de escolarização se efetiva por meio dos entes federados (União, estados e municípios), com base na estruturação de sistemas educativos próprios, pode-se afirmar que tal processo vem se efetivando, historicamente, por intermédio do binômio descentralização e desconcentração das ações educativas. Esta constatação revela o quadro complexo, relativo ao estabelecimento de parâmetros de qualidade em um cenário desigual e combinado que caracteriza a educação brasileira. Este cenário é fortemente marcado por desigualdades regionais, estaduais, municipais e locais e por uma grande quantidade de redes e normas nem sempre articuladas. (DOURADO; OLIVEIRA, 2009, p. 204).
\end{abstract}

Dessa forma, entende-se o quão imprescindível é o papel do Estado na responsabilidade pela qualidade da educação, ao passo que ele mesmo, por meio dos Planos Nacional e Estaduais de Educação, estabelece os padrões a que se espera chegar, promovendo a formação inicial e continuada de seus professores, além de fornecer toda estrutura básica para o funcionamento e favorecimento do processo de ensinoaprendizagem.

\title{
Considerações Finais
}

O propósito deste artigo foi o de investigar as políticas públicas de formação de professores enquanto variáveis que influenciam as diferenças apresentadas nos resultados educacionais, especialmente no IDEB, entre dois estados do Nordeste brasileiro: Maranhão e Ceará.

Observou-se uma disparidade entre a oferta das políticas públicas de formação de professores nos dois estados, verificando-se ainda que, para além das políticas públicas existentes, há uma série de questões a serem observadas, dentre as quais a questão socioeconômica de cada um dos estados. Esta variável, contudo, a despeito de sua relevância, não pode ser tida como principal fator de distinção do desenvolvimento educacional dos estados. Nesse sentido, de acordo com o entendimento Síveres (2010, p. 58): 
O sistema educacional está, no contexto atual, numa encruzilhada entre a demanda da técnica e a opção da ética; a fragmentação do conhecimento e a sua compreensão holística; entre transformar o conhecimento num bem privado ou garantir que seja um direito público; responder apenas o mercado ou formar, também, para o desenvolvimento social; ou acomodar-se à hegemonia global ou potencializar a energia cultural.

Para tanto, pode-se afirmar que a educação de qualidade vai para muito além das intenções que se tem para ela. Educar exige uma série de quesitos e, para este estudo, o primeiro deles é o investimento na formação de professores. Quem queremos formar? Para quem estamos formando?

Pedro Demo $(2008,2010)$ e Paulo Freire $(1996,2005)$ discutem incansavelmente sobre o papel da escola e sua função social, o papel do professor e sua função e responsabilidade na formação do aluno. Entretanto, para além de muitas outras que a ela foram atribuídas, a função primeira da escola ainda é ensinar, ou seja, o aluno vai para a escola para aprender. Os aspectos socioeconômicos e culturais contribuem para explicar grande parte do desempenho dos estudantes, pois estão intimamente relacionados, contudo, a análise aqui realizada buscou fazer um recorte entre os dados de formação de professores e resultados obtidos.

As políticas públicas estão diretamente relacionadas à construção do bem comum, ou seja, ao conjunto de ações que atendam à população de alguma forma, no que diz respeito aos direitos públicos garantidos, assegurando a todos os cidadãos as oportunidades para que esses direitos sejam de fato garantidos e respeitados. A partir daí, derivam as leis, as resoluções e os decretos governamentais.

A LDB n. 9.394/1996 foi caracterizada como um divisor de águas na educação nacional, apesar de criticada por alguns estudiosos, os quais a compreendem como indutora de uma formação generalista. Ainda assim, há que se reconhecer que as políticas implementadas a partir de sua promulgação proporcionaram um salto de qualidade no que diz respeito à formação inicial e continuada dos professores. Merecem uma análise mais apurada, no entanto, os dados aqui apresentados relativos ao Maranhão, estado em que apenas 51,5\% dos professores têm formação em nível superior, enquanto que no Ceará, 71,1\% dos professores alcançam esse nível de formação.

Os dados da formação docente dos estados em questão parecem ter relação com a tendência demonstrada pelos indicativos do IDEB 2017 (4ํㅜㄷㅜㅜ anos) de 6,2 no estado do Ceará, e 4,8 no Maranhão. Outro indicativo é o nível de aprendizagem suficiente de 
alfabetização, sendo que o Ceará apresenta 70\% de suficiência em leitura, enquanto que o Maranhão apresenta apenas 40\% de suficiência nesse quesito.

Percebe-se que mesmo as políticas públicas de formação de professores federais alcançam diferentes proporções nos estados. O PIBID, por exemplo, é ofertado em nove IES no Ceará, em cinco municípios diferentes, havendo 2.096 bolsistas, enquanto no Maranhão são apenas três IES, todas elas na capital, atendendo 916 bolsistas. 0 programa Residência Pedagógica, que no Ceará está presente em oito IES, em cinco municípios diferentes e com 2.074 residentes, mas no Maranhão há apenas três IES, todas elas na capital, com 1.282 residentes.

Além desses dados, foram apresentadas as políticas públicas de formação de professores de cada estado. Verifica-se que o quantitativo de cursos que o estado do Ceará oferece aos seus professores é maior e com uma variedade mais extensa do que o programa oferecido pelo estado do Maranhão. Nos dois casos, há no PEE uma Meta importante referente à formação de todos os professores da Educação Básica possuem ou cursam o nível superior, em parceria com a União nos cursos de Licenciatura.

Dentre os dados analisados, há de se enfatizar a equidade existente no estado do Ceará. De todos os estados brasileiros, o Ceará é o que apresenta maior equidade em relação aos resultados. Seja qual for o município, os resultados são muito próximos, pois a educação foi estabelecida como meta estadual. Por outro lado, no Maranhão há uma discrepância entre a capital, onde os maiores esforços estão concentrados, e os demais municípios. Conforme Dourado e Oliveira (2009, p. 206):

\footnotetext{
Tais considerações ratificam a necessária priorização da educação como política pública, a ser efetivamente assegurada, o que implica: aumento dos recursos destinados à educação, regulamentação do regime de colaboração entre os entes federados, otimização e maior articulação entre as políticas e os diversos programas de ações na área; efetivação da gestão democrática dos sistemas e das escolas, consolidação de programas de formação inicial e continuada, articulados com a melhoria dos planos de carreira dos profissionais da educação.
}

A formação de professores e as políticas públicas direcionadas para essa temática são uma questão histórica e muitas barreiras ainda precisam ser superadas, a começar pelo interesse daqueles que fazem as políticas públicas acontecerem. Acreditamos que quando elas realmente compuserem a agenda pública como prioridade, poderemos ver resultados mais promissores se concretizarem. 


\section{Referências}

ALVES, Andresa G. K.; COSTA-HÜBES, Terezinha da C. Formação continuada de professores e Índice de Desenvolvimento da Educação Básica: o processo e o produto.

Revista Leitura e Formação: Professores Leitores, v. 12, n. 23, 2º sem. / 2011, p. 373393. Disponível em: http://e-

revista.unioeste.br/index.php/linguaseletras/article/view/6026. Acesso em: 16 mar. 2019.

BARRETTO, Elba Siqueira de Sá. Políticas de formação docente para a educação básica no Brasil: embates contemporâneos. Revista Brasileira de Educação, v. 20. n. 62. julset de 2015. Disponível em: http://dx.doi.org/10.1590/S1413-24782015206207.

Acesso em: 16 mar. 2019.

BORGES, Maria Célia; AQUINO, Orlando Fernández; PUENTES, Roberto Valdés.

Formação de professores no Brasil: história, políticas e perspectivas. Revista HISTEDBR On-line, n. 42. p. 94-112, jun. 2011. Disponível em:

https://periodicos.sbu.unicamp.br/ojs/index.php/histedbr/article/view/8639868. Acesso em: 16 mar. 2019.

BRASIL. Constituição (1988). Constituição da República Federativa do Brasil. Disponível em: http://www.planalto.gov.br/ccivil_03/constituicao/constituicao.htm. Acesso em: 20 de abril de 2019.

BRASIL. Ministério da Educação. Instituto Nacional de Estudos e Pesquisas Educacionais Anísio Teixeira. Sinopse Estatística da Educação Superior. 2011. Disponível em: http://inep.gov.br/sinopses-estatisticas-da-educacao-superior. Acesso em: 20 abr. 2019.

BRASIL. Lei n. 9.394, de 20 de dezembro de 1996. Lei das Diretrizes e Bases da Educação Nacional. Estabelece as diretrizes e bases da educação nacional. Diário Oficial da União, Seção 1, p. 27933. Brasília, DF, 23 dez. 1996. Disponível em:

http://www.planalto.gov.b.r/ccivil_03/leis/19394.htm. Acesso em: 20 mar. 2019.

BRASIL. Congresso Nacional. Decreto n. 5.800, de 8 de junho de 2006. Dispõe sobre o Sistema Universidade Aberta do Brasil - UAB. Diário Oficial da União, Seção 1, p. 4. Brasília, DF, 9 jun. 2006. Disponível em:

http://www.planalto.gov.br/ccivil_03/_Ato2004-2006/2006/Decreto/D5800.htm. Acesso em: 26 abr. 2019.

BRASIL. Congresso Nacional. Lei n. 13.005, de 25 de junho de 2014. Aprova o Plano Nacional de Educação - PNE e dá outras providências. Diário Oficial da União - Edição Extra, de 26 de junho de 2014, n. 120-A. Disponível em: http://www.in.gov.br. Acesso em: 25 abr. 2019.

BRASIL. Edital CAPES n. 05/2018. Chamada para articulação de cursos superiores na modalidade EaD no âmbito do Programa UAB. 2018a. Disponível em: http://www.capes.gov.br/images/stories/download/editais/01032018-Edital-5-2018UAB-2.pdf. Acesso em: 28 abr. 2019. 
BRASIL. INEP. Censo Escolar 2017. Notas Estatísticas. Brasília: Inep, 2018b. Disponível em:

http://download.inep.gov.br/educacao_basica/censo_escolar/notas_estatisticas/2018/ notas_estatisticas_Censo_Escolar_2017.pdf. Acesso em: 25 mar. 2019.

BRASIL. CAPES. SISUAB. Sistema Universidade Aberta do Brasil. Disponível em: https://sisuab2.capes.gov.br/sisuab2/paginas/polo/manter-polo/consulta.xhtml. Acesso em: 28 abr. 2019.

BRAY, Mark; ADAMSON, Bob; MASON, Mark (orgs.). Pesquisa em educação comparada: abordagens e métodos. Brasília: Liber Livro, 2015.

CEARÁ. Poder Executivo. Lei n. 16.025, de 30 de maio de 2016. Dispõe sobre o Plano Estadual de Educação (2016/2024). Diário Oficial do Estado. Fortaleza, 01 de junho de 2016, Série 3, Ano VIII, N. 101, Caderno 1/3. Disponível em:

http://www.mpce.mp.br/wp-content/uploads/2016/02/20170020-LEI-160252016.pdf. Acesso em: 6 maio 2019.

CRUZ, Priscila; MONTEIRO, Luciano (orgs.). Anuário Brasileiro da Educação Básica. São Paulo: Moderna, 2018.

CUNHA, Célio da. Educação comparada: relevância e caminhos metodológicos (Prólogo) In: BRAY, Mark; ADAMSON, Bob; MASON, Mark (orgs.). Pesquisa em educação comparada: abordagens e métodos. Brasília: Liber Livro, 2015.

DEMO, Pedro. Aprender bem/mal. Campinas, SP: Autores Associados, 2008.

DEMO, Pedro. Ser professor é cuidar que o aluno aprenda. 7. ed. Porto Alegre: Mediação, 2010.

DIAS, Reinaldo; MATOS, Fernanda. Políticas públicas: princípios, propósitos e processos. São Paulo: Atlas, 2012.

DOURADO, Luiz Fernandes; OLIVEIRA, João Ferreira de. A Qualidade da Educação:

perspectivas e desafios. Caderno Cedes. Campinas, v. 29, n. 78, p. 201-205. Maio-agosto 2009. Disponível em: http://www.scielo.br/pdf/ccedes/v29n78/v29n78a04.pdf. Acesso em: 6 jul. 2019.

FREIRE, Paulo. Pedagogia da Autonomia: saberes necessários à prática educativa. São Paulo: Paz e Terra, 1996.

FREIRE, Paulo. Pedagogia do Oprimido. Rio de Janeiro: Paz e Terra, 2005.

LUCKESI, Cipriano Carlos. Prática educativa: processo versus produto. ABC Educativo: a revista da educação. Ano 6, n. 52, dezembro de 2005, p. 20-21. Abceducativo: São Paulo.

MANZON, Maria. Comparação entre lugares. In: BRAY, Mark; ADAMSON, Bob; MASON, Mark (orgs.). Pesquisa em educação comparada: abordagens e métodos. Brasília: Liber Livro, 2015. 
MARANHÃO. Poder Executivo. Lei n. 10.099, de 11 de junho de 2014. Aprova o Plano Estadual de Educação do Estado do Maranhão e dá outras providências. Disponível em: http://www.educacao.ma.gov.br/files/2016/05/suplemento_lei-10099-11-06-2014PEE.pdf. Acesso em: 6 maio 2019.

MARANHÃO. Secretaria de Estado de Educação. Escola Digna. Cadernos de Orientações Pedagógicas. Gestão Escolar. Disponível em: http://www.educacao.ma.gov.br/files/2017/05/apostila-finalproduc\%CC\%A7a\%CC\%83o.pdf. Acesso em: 6 maio 2019

MIGUEL, Maria Elisabeth Blanck; FERREIRA, Jacques de Lima. Formação de professores: história, políticas educacionais e práticas pedagógicas. Curitiba: Appris, 2015.

SÍVERES, Luiz. Educação e fraternidade. In: Escritos, Revista de Ciências Humanas. Grupo Educacional Pe. João Bagozzi, v. 6, Especial Educação, 2010.

SOUZA, Rosa de Fátima. Cruzando fronteiras regionais: repensando a história comparada da educação em âmbito nacional. In: Revista Brasileira de Educação, v. 21, n. 67, out.-dez. 2016, p. 833-850. ISSN 1413-2478. Disponível em:

http://dx.doi.org/10.1590/S1413-24782016216743. Acesso em: 6 jul. 2019. 


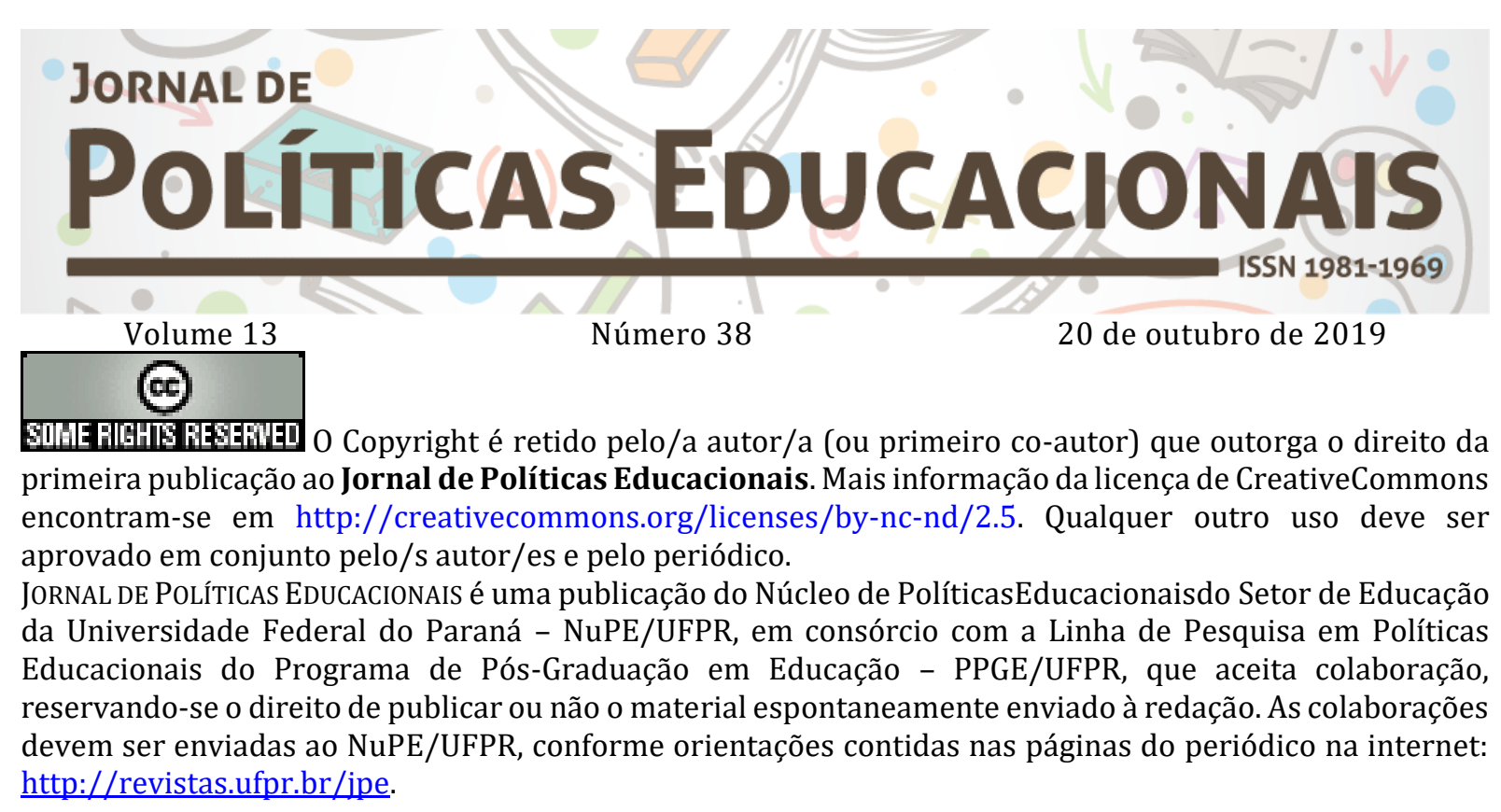

Indexação:

BBE - Biblioteca Brasileira de Educação (MEC/INEP)

Clase (Base de Datos Bibliográfica de Revistas de Ciencias Sociales y Humanidades)

Diadorim - Diretório de Política de Acesso Aberto das Revistas Científicas Brasileiras (IBICT)

Google Scholar

Index Copernicus

Portal de Periódicos (CAPES)

SER - Sistema Eletrônico de Revistas da Universidade Federal do Paraná (SER/UFPR)

Sumários de Revistas Brasileiras (FUNPEC-RP)

DRJI - Directory of Research Journals Indexing

(Periódico integralmente disponível apenas em via eletrônica)

Jornal de Políticas Educacionais / Núcleo de Políticas Educacionais da Universidade Federal do Paraná NuPE/UFPR - v.1, n. 1 (1을 semestre de 2007) - Curitiba: NuPE/UFPR.

Volume 13, número 38 - Outubro de 2019

ISSN 1981-1969

1. Educação - Periódicos. 2. Política Educacional - Periódicos. I. NuPE/UFPR

Comitê Editorial:

Elisângela Scaff (UFPR)

Daniela Oliveira Pires (UFPR)

Conselho Editorial:

Andréa Barbosa Gouveia (UFPR - Brasil), Cesar Tello (Universidad Nacional Tres Febrero, Argentina), Fernanda Saforcada (Universidad de Buenos Aires - UBA - Argentina), Gladys Beatriz Barreyro (USP Brasil), Gustavo Enrique Fischman, (Arizona State University - USA), Jefferson Mainardes (UEPG - Brasil), João Ferreira de Oliveira (UFG - Brasil), Juca Gil (UFRGS - Brasil), Luiz Souza Júnior (UFPB - Brasil), Ney Cristina Monteiro de Oliveira (UFPA - Brasil), Nicolás Bentancur, (Universidad de la República de Uruguay), 
SILVA, M. C. M. da; CERCE, L. M. R; BRITO, R. O. de. Estudo das Políticas Públicas de Formação de Professores Associado aos Resultados do IDEB dos Estados do Ceará e Maranhão

Robert Verhine (UFBA - Brasil), Rosana Cruz (UFPI - Brasil), Rubens Barbosa Camargo (USP - Brasil), Sebastián Donoso Díaz (Universidad de Talca - Chile), TheresaAdrião (UNICAMP - Brasil), Vera Peroni (UFRGS - Brasil).

Créditos e Agradecimentos:

Revisão de Língua Portuguesa, Abstract e Resumen: PROGRAMA DE APOIO ÀS PUBLICAÇÕES CIENTÍFICAS PERIÓDICAS DA UFPR

Arte e diagramação: TIAGO TAVARES (tiagotav@gmail.com)

Jornal de Políticas Educacionais

Universidade Federal do Paraná

Setor de Educação

Núcleo de Políticas Educacionais - NuPE/UFPR

Avenida Sete de Setembro, 2645

$2^{\circ}$ andar, Sala 213

80.230-010 - Curitiba - PR - Brasil

Tel.: 41-3535-6264

jpe@ufpr.br

http://revistas.ufpr.br/jpe 